\title{
USGS Reference Materials Program Serving the needs of the global analytical community
}

\section{Introduction}

Every year in the United States, millions of measurements are made on the chemical composition of items that affect us on a daily basis. The accuracy of these measurements is routinely determined by the analysis of appropriate reference materials. The composition of these reference materials has been previously determined through rigorous testing by multiple laboratories using a variety of analytical techniques. Today, reference materials help to accurately evaluate the composition of our food, water, air, the medicines we use, the soil we grow our crops in, and hundreds of other products that affect our everyday lives.

In the field of earth science, reference materials are very important because they help us develop a better understanding of the processes that have shaped, and continue to shape the world around us. Despite the importance of geological reference materials, a little more than four decades ago reliable reference materials for silicate rocks were unavailable. However, in 1951 the Massachusetts Institute of Technology (MIT) and the U.S. Geological Survey (USGS) cooperated to develop reference materials G-1 (granite) and W-1 (diabase)_producing the first readily available supply of well-characterized silicate rock materials. This early effort has since led to the development of 42 additional reference materials ranging from soils, to marine sediments, manganese nodules, and a host of diverse silicate rocks in support of USGS programs. At present,

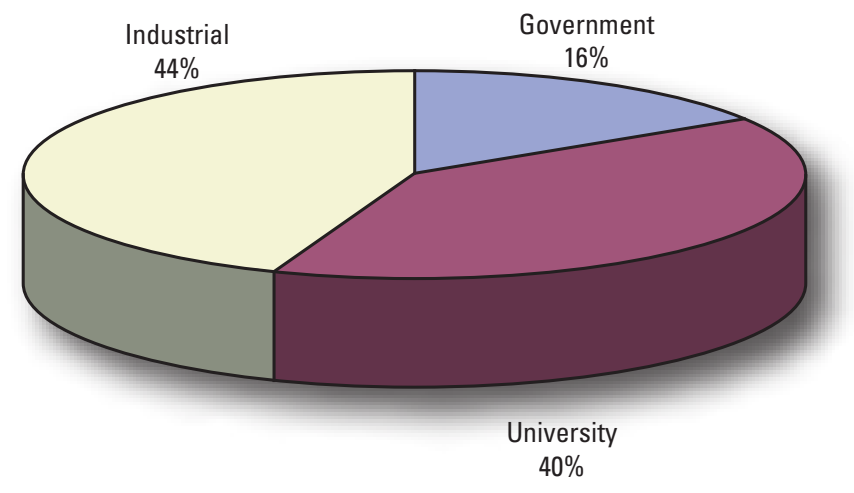

USGS reference materials are used by a variety of government, private industrial, and university laboratories.

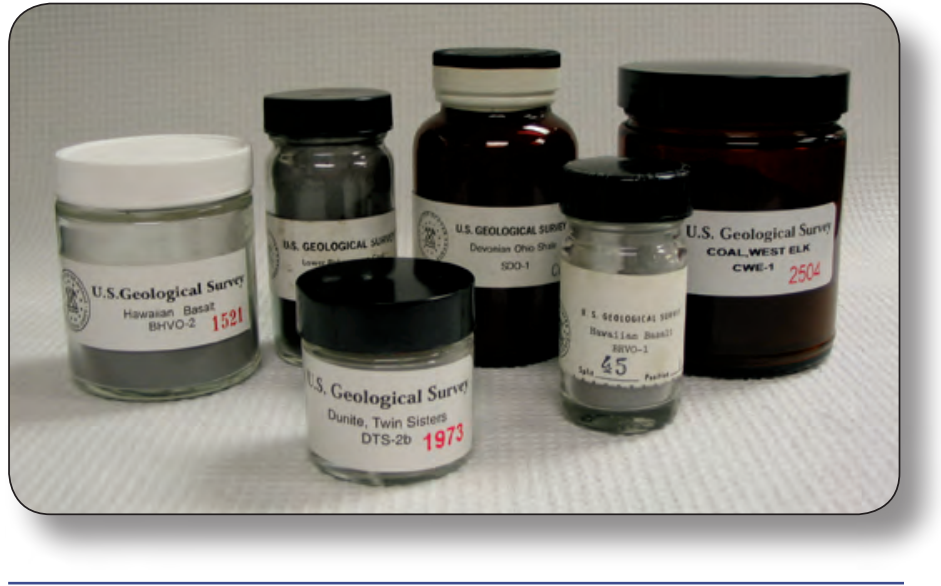

\section{USGS Geochemical Reference Materials are natural matrix materials that have been well characterized for their chemical composition.}

USGS reference materials are distributed internationally to organizations involved in geochemical and environmental analysis, instrumentation and methods development, and industrial research and quality assurance. In addition, the reference materials are widely used in the development and validation of geochemical models used by the USGS. Since the program's inception, more than 20,000 units of USGS reference materials have been distributed.

\section{How Reference Materials Are Used}

Reference materials are used by a variety of government, private, and university laboratories around the world in the development and validation of analytical measurement methodologies. The reliability of new analytical techniques is routinely verified by the analysis of appropriate reference materials, for which accurate values are known. This process rigorously evaluates the method's ability to produce accurate results.

Another important use of reference materials is in a laboratory's quality control program. A laboratory quality control program routinely evaluates a laboratory's analytical accuracy based on the analysis of "blind" reference materials (where the laboratory does not know the samples are reference materials). In these cases, reference materials that closely 


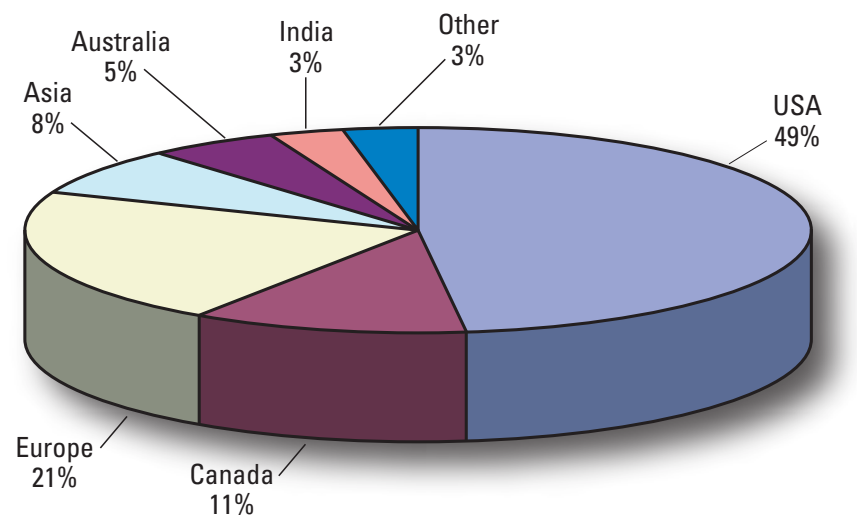

Scientists worldwide use USGS reference materials to validate analytical methods and check instrument performance.

match actual sample compositions are important in order to evaluate the laboratory's performance on real samples. In addition, many scientists submitting samples to either commercial or in-house laboratories may include reference materials in with their samples as an immediate check on laboratory accuracy.

Because many different analytical techniques are used to determine the "certified value" of the reference material, the reference materials can be used in a wide variety of analytical techniques, including those that perform direct sample analysis, such as XRF (X-ray fluorescence spectroscopy) and INAA (instrumental neutron activation analysis), as well as those that require the sample to be prepared in some manner (usually via an acid digestion) such as ICP-OES (inductively coupled plasma optical emission spectroscopy) or ICP-MS (inductively coupled plasma mass spectrometry). The geochemical reference materials produced by the USGS are utilized by scientists throughout the world to validate their methods and procedures.

As new techniques are developed and we continue to perform more measurements on substances that affect our everyday lives, the use of reference materials has steadily increased. During the last 10 years, the number of USGS reference materials shipped to users has increased, on average, by 14 percent annually-indicating a growing need for reference materials.

\section{Preparation of Reference Materials}

The exact procedures for making reference materials vary, depending on the starting materials and the final physical form of the reference material. The first step is to identify what type of material is needed and what elemental content it should have. Generally, the need for a new reference material is identified through requests from public and private sector groups as well as by USGS and other government agency scientists.
Once a need is established (for example, "trace elements in shale"), potential collection sites are identified using information from the USGS National Geochemical Database and other sources, followed by a field trip to the site to collect test samples. Generally, the starting material is a natural geologic deposit from a location in the United States which meets the general composition requirements-this is where the reference materials produced by the USGS are unique compared to those from many other suppliers. If analysis of the test samples indicates that the material is suitable, the site is revisited for full-scale collection activities. A sufficient quantity of the material is then harvested and brought back to the USGS laboratory in Denver, Colorado. In the laboratory, as much as 1,000 pounds of base material is pulverized and ground into a fine powder. The finely ground powder is mixed to ensure homogeneity and then split into individual 30-100 gram bottles using a custom-designed spinning riffler sampling device. The natural matrix reference material is then labeled and put into storage. Due to the labor-intensive nature of producing, analyzing, and certifying a new reference material, it is USGS policy to produce enough material to last a minimum of 20 years. This approach allows scientists to monitor long-term trends in chemical analysis, provides the community with wellcharacterized materials that are important links to historical studies, and allows for reliable intra-laboratory comparisons of new techniques.

In the past several years, an increased interest in direct trace elemental analysis of solids at the micrometer scale using Laser Ablation ICP-MS and Electron/Ion Microprobe analysis has brought a new set of challenges to the field of reference material development. In order to calibrate these

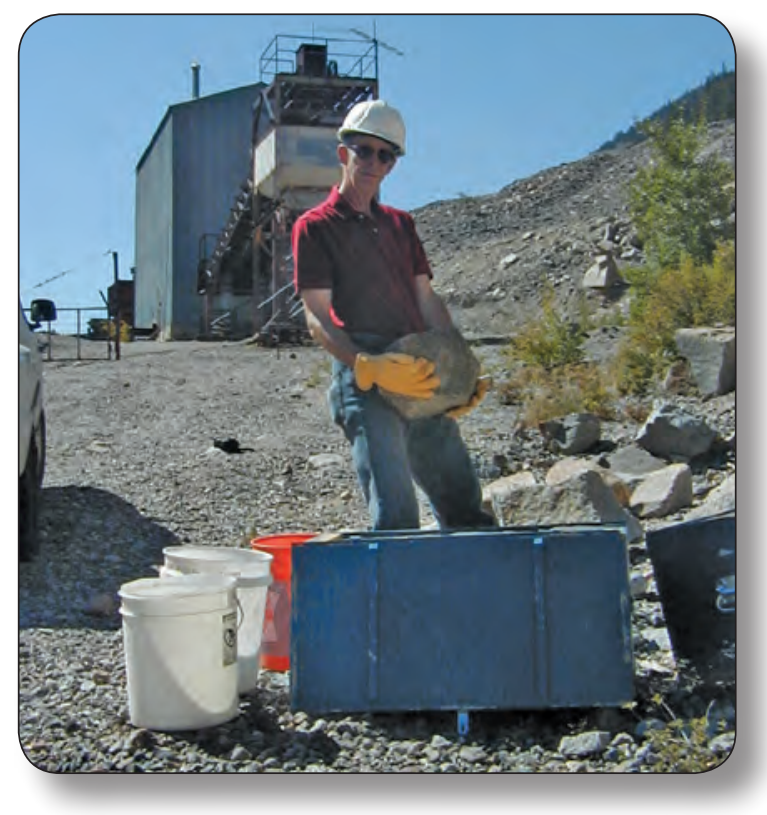

Steve Wilson (USGS, Denver) collecting base material to be used in the preparation of a new reference material. 
instruments, a new generation of reference materials is required with element homogeneity at the micrometer scale. This micro-homogeneity requirement generally cannot be achieved using conventional powdered materials. In addition, these new materials must be prepared in sufficient quantities to allow for the generation of long-term intra-laboratory data for method validation.

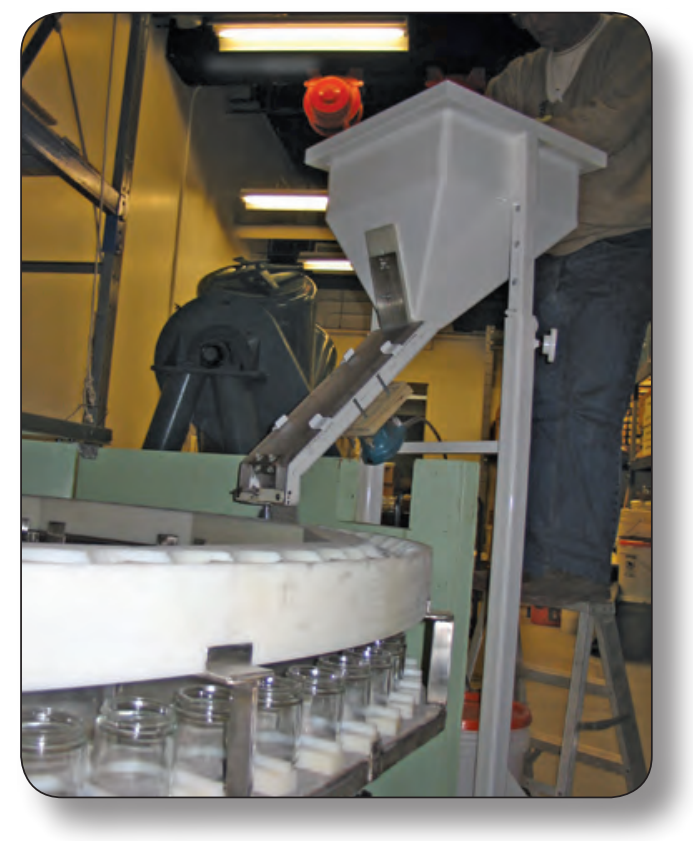

The spinning riffler sampler fills bottles with prepared reference material.

The USGS has developed two innovative approaches for preparing microanalytical reference materials - reaffirming the USGS as a leader in solid reference material development for the global scientific community. In the first approach, a powdered material is melted in a high-temperature furnace and then flashcooled to prevent crystallization. The resulting glass-like material retains the same chemical composition as the starting material, and the resulting homogeneity at the 10-20 micrometer scale is sufficient to meet the demands of many microanalytical procedures. The resulting solid material is then reduced to pieces of a suitable size and then mounted into a support substrate. This type of reference material is in increasing demand by the analytical community for calibrating instrumentation.

When no natural materials exist with sufficient micro-scale homogeneity or a material cannot be converted to the glassy form, other avenues for generating solid reference materials are explored. In a second approach, a chemical precipitation procedure is used to produce a synthetic material with a well-defined elemental composition at predetermined concentrations. Using this procedure, the USGS has developed a series of matrixspecific microanalytical reference materials with a homogeneity and trace-element chemistry suitable for calibrating Laser Ablation ICP-MS instrumentation. These precipitated powder

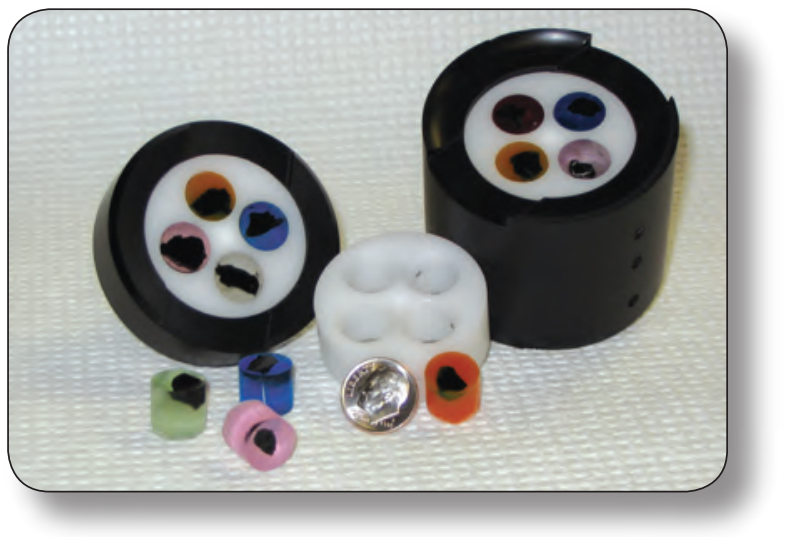

Microanalytical basaltic glass reference materials for Laser Ablation ICP-MS calibration, mounting disks, and laser sample holders.

microanalytical reference materials are produced as pellets that will fit in a standard laser ablation chamber. In addition, microanalytical reference materials have been developed with compositions similar to coral (MACS series), bone (MAPS series), polymetallic sulfides (MASS series), and wood/organic materials (MAOS series). These materials are currently used extensively in environmental studies as well as investigations into ore deposit formation. Additional materials produced by this method are currently under development.

Once a new standard has been prepared, it must be analyzed and certified before it can be distributed. Samples of the new standard are sent to a select group of USGS, government, academic, and private laboratories for analysis. The laboratories are selected by their ability to perform high-quality analyses using a variety of analytical techniques, including NAA (neutron activation analyses), TIMS (thermal ionization mass spectrometry), ICP-OES, ICP-MS, and other specialized techniques. When the results from these analyses are received, they are tabulated and statistically analyzed to obtain the certified concentration value for each component. The certificate is prepared and the reference material is then ready for shipment. The entire development process can take as long as 1 year to produce a new reference material.

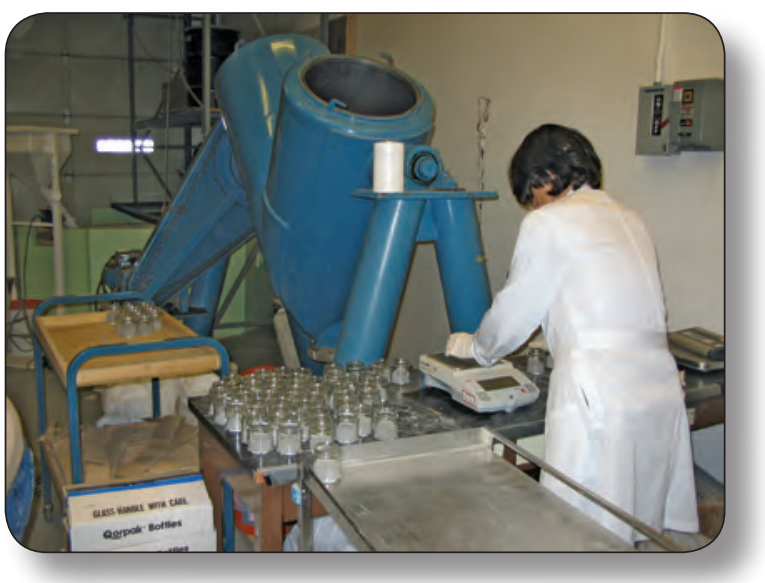

Visiting scientist from Brazil working on a new reference material. 


\section{Currently Available Reference Materials}

The majority of USGS reference materials are based on silicate rocks that were collected from the continental United States and Hawaii. These reference materials range in composition from basalt to shale. The selection of reference materials available has diversified through time in response to changes in USGS needs, requests from other government agencies, and inquiries from public sector scientists. This diversification is driven by the need to match reference materials with sample type. For example, requests from the oceanographic community led to the development of a deep-ocean marine sediment and two manganese nodule reference materials.

Inquiries from the mining industry initiated the development of several geochemical exploration standards (GXR series) that are widely used to help in the discovery of various ore deposits. In response to specific environmental studies, the USGS has developed a freshwater-sediment reference material that has a high concentration of extractable selenium. This reference material is useful in western agricultural studies where selenium in agricultural runoff can be a significant environmental issue. Currently, the production of microanalytical reference materials for use with direct solid sampling techniques, such as Laser Ablation ICP-MS, and the replacement of depleted reference materials are among the priorities of the reference materials program.

\begin{tabular}{|l|l|}
\hline \multicolumn{2}{|c|}{ Powdered Geochemical Reference Materials } \\
\hline AGV-2 Andesite & GSP-2 Granodiorite \\
\hline BCR-2 Basalt & NOD-A-1 Mn Nodule \\
\hline BHVO-2 Basalt & NOD-P-1 Mn Nodule \\
\hline BIR-1 Basalt & SDC-1 Mica Schist \\
\hline COQ-1 Carbonatite & QLO-1 Quartz Latite \\
\hline CLB-1 Coal & SGR-1 Shale \\
\hline SDO-1 Oil Shale & SCo-1 Cody Shale \\
\hline DNC-1 Dunite & W-2A Diabase \\
\hline RGM-2 Rhyolite & BSK-1 Sediment \\
\hline \multicolumn{1}{|c|}{ Microanalytical Reference Materials } \\
\hline MACS-1 coral matrix & BIR-1G basalt glass \\
\hline MAPS-1 bone matrix & GSA-1G synthetic glass \\
\hline MASS-1 sulfide matrix & GSC-1G synthetic glass \\
\hline MAOS-1 organic matrix & GSD-1G synthetic glass \\
\hline BCR-2G basalt glass & GSE-1G synthetic glass \\
\hline BHVO-2G basalt glass & \\
\hline
\end{tabular}

\section{Partial listing of USGS Geochemical Reference Materials available. See website for complete listing and more information.}

In addition to the development of our own reference materials, the USGS assists other Federal agencies in the preparation of specific reference materials. The Environmental Protection Agency (EPA) has utilized the expertise of the USGS in order to develop proficiency samples used to evaluate laboratory analysis of asbestos in soils. The National Institute for Standards and Technology (NIST) has made extensive use of USGS capabilities, co-producing numerous reference materials ranging from soils to marine sediments to an industrial sludge. The USGS reference materials program has also assisted other countries in the development of standards. Most recently, the USGS assisted Brazilian scientists in the preparation of a basalt reference material for geochemical analysis.

\section{Future Needs and Directions}

As new analytical techniques develop, new reference materials will be needed in order to validate methods, calibrate instrumentation, and ensure production of quality data. New direct solid analysis techniques such as Laser Ablation ICP-MS and Laser Induced Breakdown Spectroscopy (LIBS) will require solid reference materials for use in instrument calibration and verification. As the responses obtained for each element by these direct analysis techniques can vary greatly depending on the concentrations and identity of matrix elements present, matrix-specific reference materials will be necessary.

With continuing studies of the Earth and how the effects of our interactions with it impact our everyday lives, scientists have come to realize that determining the total concentration of an element is not enough. The interactions that can occur between an element and the environment or a living organism will depend on the chemical form of the element; thus, determining which elemental species are present is also important. As these speciation analyses (the determination of the form of an element present in a sample, such as hexavalent chromium or trivalent chromium) become more routinely used, solid geochemical reference materials with specific element species concentration information will be necessary for developing and validating analytical methods.

The use of reliable reference materials by the public and private sectors will continue to expand and be an integral part of international efforts to standardize analytical techniques now and in the future. In response to this global need, the USGS Reference Materials Program will continue to produce relevant and well-characterized natural matrix geologic reference materials that will lead to more accurate scientific analyses.

\section{Contact Information}

For more information regarding the USGS

Reference Materials Program, please see our website at: http://minerals.cr.usgs.gov/geo_chem_stand/index.html

\section{or contact:}

Dr. Stephen A. Wilson

U.S. Geological Survey

Box 25046, MS 964D

Denver Federal Center

Denver, CO 80225

Tel: 303-236-2454

e-mail: (swilson@usgs.gov)

Written by Ruth E. Wolf and Stephen A. Wilson 